\title{
Increasing uptake of colorectal cancer screening in Korea: a population-based study
}

\author{
Kui Son Choi', Jae Kwan Jun'1, Hoo-Yeon Lee', Myung-Il Hahm², Jae Hwan Oh³ and Eun-Cheol Park*1
}

\begin{abstract}
Background: Colorectal cancer (CRC) screening rates are low in most Asian countries and remain largely unknown. This study examined trends in CRC screening rates after the introduction of the Korean National Cancer Screening Programme (NCSP) and determined the factors associated with uptake of CRC screening by test modality over time.

Methods: An annual population-based survey conducted through nationally representative random sampling from 2005-2008. In total, 3,699 participants from the 2005-2008 surveys were selected as study subjects. Face-to-face interviews were performed to assess the utilization rate of CRC screening by each screening modality.

Results: Overall, CRC screening within the recommended time interval increased significantly from 22.9\% in 2005 to $36.6 \%$ in $2008(p<0.001)$. The proportion of subjects receiving a fecal occult blood test (FOBT) test within the previous year increased significantly from $7.2 \%$ in 2005 to $21.3 \%$ in $2008(p<0.001)$. Increases in FOBT testing were highest among those who had a lower income status (relative difference $=511.9 \%$ ) and women (relative difference $=266.1 \%$ ). Endoscopy use also increased from 18.0\% in 2005 to 20.5\% in 2008, albeit not significant. Overall, those who were male, non-smokers, 60-69 years old, and had a higher income status were more likely to have undergone up-to-date endoscopy and CRC screening.

Conclusions: This study revealed a substantial increase in up-to-date CRC screening in the general population from 2005 to 2008. However, more than half of adults in Korea are still not up-to-date with their CRC tests. It will be important to continue to investigate factors associated with up-to-date CRC screening by each modality.
\end{abstract}

\section{Background}

Worldwide, colorectal cancer (CRC) is the fourth most commonly diagnosed cancer in men and third in women [1]. About 1 million new cases of CRC were diagnosed in 2002 (9.4\% of all cancer diagnoses worldwide) [1]. However, at least a 25 -fold variation in the occurrence of CRC has been reported worldwide. Western countries have the highest incidence rates [2]. Recently, CRC incidence rates have been increasing rapidly in countries where the overall risk was once low (especially in Asia), whereas rates in high-risk countries are either increasing gradually, stabilizing (North and West Europe), or declining over time (North America) [3]. In Korea, incidence rates have risen markedly over the past few years (e.g., annual percent change, APC $=7.3 \%$ per year between 1999 and 2005) $[4,5]$. From 2003 to 2005, CRC was the third most com-

* Correspondence: ecpark@ncc.re.kr

1 National Cancer Control Institute, National Cancer Center, 111, Jungbalsan-ro, Ilsandong-gu, Goyang-si, Gyeonggi-do, Korea

Full list of author information is available at the end of the article monly diagnosed cancer in Korea $(12.0 \%$ of all cancer diagnoses) [5].

Based on evidence that screening reduces CRC incidence and mortality [6-9], national guidelines in several countries now recommend regular CRC screening for average-risk persons aged $\geq 50$ years using one or more of the following options: annual fecal occult blood test (FOBT), flexible sigmoidscopy every 5 years, a combination of FOBT (or fecal immunochemical test) and flexible sigmoidoscopy (FSIG), colonoscopy every 10 years, and/ or double-contrast barium enema (DCBE) every 5 years $[10,11]$. Although the incidence of CRC is increasing rapidly in Asian countries, national guidelines for CRC screening are nonexistent in most Asian countries [12]. Recently, the Asia Pacific Working Group on Colorectal Cancer reached a consensus to develop guidelines for CRC screening and recommend FOBT, FISG, and colonoscopy as the best options [13].

In 2002, the National Cancer Center in Korea, and Korean Society of Coloproctology developed guideline 
for CRC screening in average-risk adults [14]. This guideline recommends that average-risk adults begin screening for CRC at age 50, having either (a) a colonoscopy every 5-10 years or (b) DCBE combined with FSIG every 5-10 years. In 2004, the Korean government also introduced nationwide CRC screening as part of the National Cancer Screening Programme (NCSP) for low-income groups. Due to capacity related to performing colonoscopy screenings on every age-eligible person, the NCSP provides an annual FOBT (immunochemical) test as the initial mass screening method for men and women $\geq 50$ years instead of colonoscopy [15]. The NCSP provides further investigation with a colonoscopy or DCBE for any low-income individual with a positive FOBT result. In 2004, Medical Aid recipients and National Health Insurance (NHI) beneficiaries within the lower $30 \%$ income bracket were eligible for free-of-charge FOBT screening services for CRC under NCSP. In 2005, the NCSP expanded its target population to the $50 \%$ income bracket. Apart from these organized CRC screening programmes, FOBT, DCBE, and colonoscopy testing are conducted in outpatient clinics or private health-assessment centers for opportunistic screening. However, in these cases individuals must pay all procedure-related costs.

Despite the evidence that screening can reduce the incidence of and mortality from CRC, uptake of CRC screening has been lower than for other mass cancer screening interventions [16,17]. Globally, only half the eligible population undergoes CRC screening [18-22]. In particular, screening for CRC is not commonly practiced in most Asian countries, and CRC screening behaviors in Asian populations remains largely unknown. Although national CRC screening programms have been offered since 2004 in Korea, no studies have reported the extent to which various CRC screening procedures have been used by the general population. In addition, no studies have analyzed whether usage of various types of screening procedures has changed over time since the introduction of the national CRC screening programme.

This study assessed the rates of CRC screening in Korea by screening modalities using a population-based survey. In particular, it examined trends in CRC screening rates after the introduction of the NCSP using four independent cross-sectional, nationally representative datasets collected during 2005-2008, and identified the factors associated with uptake of CRC screening by test modality.

\section{Methods}

\section{Study Population}

This study was based on the 2005, 2006, 2007, and 2008 Korean National Cancer Screening Survey (KNCSS). The KNCSS is an annual cross-sectional survey that uses a nationally representative random sampling to investigate Korean participation rates in cancer screening for five common cancers: gastric, liver, colorectal, breast, and cervical [23]. In each study year, women aged $\geq 30$ years old and men aged $\geq 40$ years old were selected from the Resident of Registration Population data of the Korea National Statistical Office using a stratified, multistage, and random sampling procedure according to geographic area, age, and gender. Face-to-face interviews were performed.

In 2005, a total of 2,052 men (aged $\geq 40$ years) and women (aged $\geq 30$ years) completed the interview (response rate, 40.0\%); in 2006, 2,033 (response rate, $43.4 \%$ ), in 2007, 2,022 (response rate, $47.3 \%$ ), and in 2008, 2,038 subjects (response rate, $47.6 \%$ ) completed the interview (Figure 1). Of the respondents, this study analyzed data from cancer-free male and female subjects aged $\geq 50$ years, the NCSP's recommended starting age for CRC screening among persons at average risk [15]. Further, respondents $(n=42)$ who had undergone CRC screening because of a health problem or as a follow-up to a previously identified colorectal problem were excluded from the analysis since the focus of the study is on routine screening. In total, 3,699 participants from the 2005-2008 surveys were selected as study subjects. This study was approved by the institutional review board of the National Cancer Center, Korea.

\section{Measures}

Questions were developed to assess the utilization rate of CRC screening by each screening modality. Questions were prefaced with a two-to-three-sentence description of the tests to help respondents differentiate among the tests. The following main distinguishing characteristics of the tests were provided: (a) FOBT is a test to find blood using your stool sample. This test may use a special kit at home or container to store your stool and send it to a medical center; (b) endoscopy (e.g., sigmoidoscopy and colonoscopy) is performed with a flexible tube passed through the anus (we did not distinguish between colonoscopy and sigmoidoscopy because lay people usually do not differentiate between these two tests.); (c) DCBE is a radiological exam that looks for polyps or cancer in the colon or rectum. During this procedure, a physician administers a liquid with barium through the anus and into the rectum and colon and takes $\mathrm{x}$-rays.

Previous CRC screening experience was assessed by asking respondents: (a) whether they had ever been screened for CRC, (b) when they underwent their most recent screening, and (c) which tests they underwent during their most recent CRC screening (FOBT, endoscopy, or $\mathrm{DCBE})$. A respondent was considered to be "up-todate" if he or she had undergone an FOBT test within the 
18,374 subjects aged $\geq 30$ yrs women and $\geq 40$ yrs men

$2005(\mathrm{n}=5,131) ; 2006(\mathrm{n}=4,687)$

$2007(\mathrm{n}=4,275) ; 2008(\mathrm{n}=4,281)$

Average response rate: $44.3 \%$

Excluded $(\mathrm{n}=10,229)$

- Refused to participate $(n=6,100)$

- Incomplete survey $(n=1,147)$

- Not meeting including criteria $(n=2,982)$

8,145 subjects with no previous cancer diagnosis underwent interview survey

$2005(\mathrm{n}=2,052,40.0 \%) ; 2006(\mathrm{n}=2,033,43.3 \%)$ $2007(\mathrm{n}=2,022,47.3 \%) ; 2008(\mathrm{n}=2,038,47.6 \%)$

Study inclusion rate: $45.4 \%$

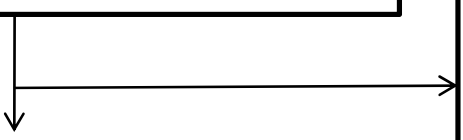

Excluded $(n=4,446)$

\section{3,699 subjects aged 50-79 yrs old men and women included final analysis}

$2005(\mathrm{n}=927,45.2 \%) ; 2006(\mathrm{n}=944,46.4 \%)$; $2007(\mathrm{n}=906,44.8 \%) ; 2008(\mathrm{n}=922,45.2 \%)$

- Men and women aged $<50 \mathrm{yrs}$ and $\geq 80$ yrs $(\mathrm{n}=4,299)$

- Missing information for income $(\mathrm{n}=105)$

- Respondents who had undergone CRC screening because of a health problem $(n=42)$

Figure 1 Participant selection process

past 1 year, an endoscopy test within the past 10 years, or a DCBE test within the past 5 years.

This survey also included demographic and socioeconomic factors (e.g., gender, age, education, and household income) associated with the uptake of CRC screening. Household income was categorized into three groups based on monthly post-tax household income (US\$1 = 1000 won). We also included questions about health insurance status. In Korea, every citizen, with the exception of some medical aid beneficiaries, is insured by the $\mathrm{NHI}$ programme. Thus, subjects were classified as "NHI beneficiary" or as "medical aid beneficiary." With regard to health behavior, we ascertained smoking status. Subjects were classified as current smokers if they reported current smoking for at least 1 year or as non-smokers if they had never smoked or had previously smoked but had not smoked for at least the past 1 year. Health status was measured by self-report; respondents rated their general health status on a five-point scale $(1=$ very poor, $5=$ excellent).

\section{Statistical analysis}

Descriptive statistics were computed for all socioeconomic factors and health behaviors. We calculated CRC screening rates from 2005 to 2008 for each screening method. First, we weighted samples by the appropriate weight based on age and gender from the 2005 Korean standard population [24]. Age- and gender-adjusted logistic regression models were used to assess the odds of having CRC screening by FOBT, endoscopy, and any test within the guidelines. Further trends were examined using the Cochran-Armitage trend test.

Changes in CRC testing between 2005 and 2008 were assessed by comparing the rates from 2005 with the rates in 2008 as relative risks. These risks are reported as the percentage changes ([relative risk - 1] $\times 100)$ in rates between the two years. Percentages were compared using Fisher's exact test.

Multivariate logistic regression was used to determine the factors associated with CRC screening procedure use by FOBT, endoscopy, any test within guidelines. Initially, separate models were tested for each outcome from the 2005-2008 survey samples, followed by models that included all the samples with time as an indicator variable. Because the results were similar when using separate models versus one, we focused the analyses on combined models. We did not include health insurance type as a variable in the final multivariate model because of its strong correlation with monthly household income. To maintain a family $\alpha$ of 0.05 for the analyses of the 3 outcomes, we employed a Bonferroni adjustment using $\alpha$ $=0.05 / 3=0.017$. All statistical analyses were conducted 
using SAS statistical software (version 9.1; SAS Institute Inc., Cary, NC).

\section{Results}

Table 1 presents descriptive data about the study participants. The demographic distribution of the sample was almost homogenous among survey years, with the exception of household income and health insurance status. A larger proportion of 2008 survey respondents reported higher income compared to 2005 survey respondents.

Table 2 presents the proportion of subjects who reported CRC testing. The proportion reporting FOBT testing within the previous year increased significantly from $7.2 \%$ in 2005 to $21.3 \%$ in $2008(p<0.001)$. Rates of endoscopy use also increased from $18.0 \%$ in 2005 to $20.5 \%$ in 2008 , albeit not significant $(p=0.060)$. Overall, CRC screening within the recommended time interval increased significantly from $22.9 \%$ in 2005 to $36.6 \%$ in $2008(p<0.001)$.

Tables 3 show changes in FOBT and endoscopy uses between 2005 and 2008, comparing 2005 rates with 2008 rates as relative risks. The results indicate an increased proportion of FOBT use from 2005 to 2008 in all study population. In particular, increases in FOBT testing were highest among those with lower income status (relative difference percentage $=511.9 \%$ ) and women (relative difference percentage $=266.1 \%$ ).

The results from the full logistic regression models for FOBT (model 1), endoscopy (model 2), and any test (model 3) are shown in Table 4. Rates of FOBT testing and any CRC testing were significantly increased in 2008 compared to 2005 at the adjusted $\alpha$ of 0.017 . With regard FOBT test, those who aged 60-69 years, and reported their health status as "excellent/very good" were more likely to have undergone FOBT testing. Endoscopies were

Table 1: Characteristics of respondents, 2005-2008 $(n=3,699)$

\begin{tabular}{|c|c|c|c|c|c|}
\hline & $2005(n=927)$ & $2006(n=944)$ & $2007(n=906)$ & $2008(n=922)$ & $P$ value \\
\hline & $\%$ & $\%$ & $\%$ & $\%$ & \\
\hline \multicolumn{6}{|l|}{ Gender } \\
\hline Male & 46.8 & 46.9 & 47.1 & 47.3 & 0.997 \\
\hline Female & 53.2 & 53.1 & 52.9 & 52.7 & \\
\hline \multicolumn{6}{|l|}{ Age (years) } \\
\hline $50-59$ & 47.8 & 48.4 & 48.8 & 49.3 & 0.972 \\
\hline $60-69$ & 33.6 & 32.6 & 31.8 & 31.3 & \\
\hline $70-79$ & 18.6 & 19.0 & 19.4 & 19.4 & \\
\hline \multicolumn{6}{|l|}{ Education (level) } \\
\hline Did not complete high school & 62.9 & 63.1 & 60.3 & 59.1 & 0.153 \\
\hline High school graduate or above & 37.1 & 36.4 & 39.7 & 40.9 & \\
\hline \multicolumn{6}{|l|}{ Monthly household income (US\$) } \\
\hline Less than 1,500 & 24.7 & 27.1 & 21.4 & 20.9 & 0.002 \\
\hline $1,500-3,000$ & 55.1 & 48.6 & 52.1 & 51.2 & \\
\hline 3,000 or more & 20.2 & 24.3 & 26.5 & 27.9 & \\
\hline \multicolumn{6}{|l|}{ Health insurance type } \\
\hline Medical aid & 5.1 & 7.8 & 4.1 & 5.3 & 0.005 \\
\hline National Health Insurance & 94.9 & 92.2 & 95.9 & 94.7 & \\
\hline \multicolumn{6}{|l|}{ Self-reported health status } \\
\hline Fair/poor & 16.8 & 15.8 & 15.2 & 12.7 & 0.277 \\
\hline Good & 28.7 & 28.0 & 27.8 & 28.3 & \\
\hline Excellent/very good & 54.5 & 56.2 & 57.0 & 59.0 & \\
\hline \multicolumn{6}{|l|}{ Smoking status } \\
\hline Never smoked & 23.9 & 23.1 & 22.7 & 20.3 & 0.391 \\
\hline Former smoker & 14.8 & 13.1 & 14.6 & 16.1 & \\
\hline Current smoker & 61.3 & 63.8 & 62.7 & 63.6 & \\
\hline
\end{tabular}


Table 2: Colorectal cancer screening rates in 2004, 2005, 2006, and 2008.

\begin{tabular}{|c|c|c|c|c|c|c|}
\hline & \multicolumn{2}{|c|}{ FOBT within previous year } & \multicolumn{2}{|c|}{$\begin{array}{l}\text { Endoscopya within previous } 10 \\
\text { years }\end{array}$} & \multicolumn{2}{|c|}{ Any testb within recommended time interval } \\
\hline & Percent & OR $(95 \% \mathrm{Cl}) \mathrm{c}$ & Percent & OR $(95 \% \mathrm{Cl}) \mathrm{c}$ & Percent & OR $(95 \% \mathrm{Cl}) \mathrm{c}$ \\
\hline 2005 & 7.2 & 1.00 (referent) & 18.0 & 1.00 (referent) & 22.9 & 1.00 (referent) \\
\hline 2006 & 13.1 & $2.15(1.57-2.96)$ & 16.5 & $0.94(0.74-1.19)$ & 26.8 & $1.32(1.07-1.64)$ \\
\hline 2007 & 17.5 & $3.03(2.23-4.12)$ & 18.0 & $1.06(0.83-1.34)$ & 29.0 & $1.46(1.18-1.80)$ \\
\hline 2008 & 21.3 & $3.68(2.72-4.97)$ & 20.5 & $1.21(0.96-1.53)$ & 36.6 & $2.02(1.64-2.48)$ \\
\hline$P_{\text {trend }}{ }^{\mathrm{d}}$ & & $<0.001$ & & 0.060 & & $<0.001$ \\
\hline $\begin{array}{l}\text { Flexible } \\
\text { Include } \\
\text { creenec } \\
\text { Age an } \\
p \text {-value }\end{array}$ & $\begin{array}{l}\text { idoscopy } \\
\text { test withi } \\
\text { not equal } \\
\text { ler adjuste }\end{array}$ & $\begin{array}{l}\text { colonoscopy. } \\
\text { he past one year, enc } \\
\text { sum of participants } \\
\text { gistic regression mo }\end{array}$ & $\begin{array}{l}\text { py test within } \\
\text { use people m } \\
\text { or each outcc }\end{array}$ & $\begin{array}{l}\text { e past } 10 \text { years, or DCE } \\
\text { nave had more than o } \\
\text { e were estimated. }\end{array}$ & $\begin{array}{l}\text { E test within } t \\
\text { e test. }\end{array}$ & 5 years. The number \\
\hline
\end{tabular}

significantly more likely among those aged 60-69 years, those with higher income, and non-smokers. Women were significantly less likely to have had an endoscopy test. Overall, male, individuals aged 60-69 years, those with higher income, and non-smokers were more likely to have undergone up-to-date CRC screening.

\section{Discussion}

Early detection and treatment is an important way to reduce mortality from colorectal cancer. Nonetheless, Asians tend to have little understanding about CRC screening. This report is the first to assess CRC screening rates by various screening methods in a Korean population at average risk for the disease. Data from national surveys reveal that CRC screening remains underused in Korea: in 2008 , only $36.6 \%$ of the Korean population aged $\geq 50$ years had undergone CRC screening within the recommended time interval. In contrast, data from the National Health Interview Survey indicate that in the United States, $44 \%$ of adults aged 50 to 64 years had undergone a recommended CRC screening test in 2005 [25].

However, the current analysis revealed a substantial increase in up-to-date CRC screening in the general population from 2005 to 2008. In addition, it showed substantial changes in the proportion of the general population being screened by different screening modalities. In 2005, only $23 \%$ of the Korean population was screened by FOBT, endoscopy (colonoscopy and/or sigmoidoscopy), and/or DCBE within guidelines. Screening rates did increase over the 3-year period, yet by 2008 still only $36.6 \%$ of respondents had been screened by 'any test' within guidelines. The majority of this increase was explained by a $14 \%$ increase in screening FOBT, yet there was only a $2.5 \%$ increase in endoscopy. Although endoscopy testing increased only slightly between 2005 and 2008 (relative difference percentage $=14 \%$ ), FOBT testing rates increased relatively more during the same period (relative difference percentage $=196 \%$ ). By 2008, FOBT had become the most common CRC screening test modality. In contrast, in the United States the prevalence of CRC screening using endoscopy was more than twice that using FOBT [25]

The large increases in FOBT use can be explained in part by health care policy and public awareness. Since 2004, the Korean government and NHIC have provided free-of-charge annual FOBT testing as an initial screening tool for low-income individuals. The current analysis revealed that the greatest increases in FOBT use were among individuals with low household income (relative difference percent $=512 \%$ ). Further, FOBT testing increased $266 \%$ among women from 2005 to 2008. These results suggest that the substantial increase in FOBT testing among women and low-income groups might have been associated with the introduction of the NCSP. The current analysis also revealed that endoscopy screening rates increased slightly from 2005 to 2008. These relatively small increases in endoscopy use can be attributed in part to the fact that the NHI only reimburses colonoscopy and sigmoidscopy testing for those with symptoms or colorectal problems. Other health or educational policies, e.g., mass-media campaigns might have impacted on the increment of the CRC screening rates.

Consistent with previously published literature regarding CRC screening, we have shown that test use varies by gender, age, income, smoking status [16,18-22]. Interestingly, respondents with higher income levels were more likely to have an endoscopy test. Under the Korean health 
FOBT within the previous year

Endoscopya within the previous 10 years

\begin{tabular}{|c|c|c|c|c|c|c|c|c|c|}
\hline \multirow[b]{2}{*}{$2005 \%$} & \multirow[b]{2}{*}{$2008 \%$} & \multicolumn{3}{|c|}{2008 vs 2005} & \multirow[b]{2}{*}{$2005 \%$} & \multirow[b]{2}{*}{$2008 \%$} & \multicolumn{3}{|c|}{2008 vs 2005} \\
\hline & & $\begin{array}{l}\text { Relative } \\
\text { Difference } \\
\% \text { b }\end{array}$ & $\begin{array}{l}\text { Absolute Difference } \\
\text { percentage points }\end{array}$ & P value & & & $\begin{array}{l}\text { Relative } \\
\text { Difference } \\
\%^{b}\end{array}$ & $\begin{array}{l}\text { Absolute } \\
\text { Difference } \\
\text { percentage } \\
\text { points }\end{array}$ & $P$ value \\
\hline
\end{tabular}

\begin{tabular}{|c|c|c|c|c|c|c|c|c|c|c|}
\hline \multicolumn{11}{|l|}{ Gender } \\
\hline Male & 8.7 & 21.0 & 141.4 & 12.3 & $<0.001$ & 18.2 & 19.3 & 6.0 & 1.1 & 0.756 \\
\hline Female & 5.9 & 21.6 & 266.1 & 15.7 & $<0.001$ & 17.8 & 21.6 & 21.3 & 3.8 & 0.156 \\
\hline \multicolumn{11}{|l|}{ Age (years) } \\
\hline $50-59$ & 6.4 & 19.4 & 203.1 & 13.0 & $<0.001$ & 17.1 & 21.3 & 24.6 & 4.2 & 0.132 \\
\hline $60-69$ & 7.7 & 22.5 & 192.2 & 14.8 & $<0.001$ & 19.9 & 21.5 & 8.0 & 1.6 & 0.675 \\
\hline 70-79 & 8.4 & 24.0 & 185.7 & 15.6 & $<0.001$ & 16.9 & 16.6 & -1.8 & -0.3 & 0.938 \\
\hline \multicolumn{11}{|l|}{ Education (level) } \\
\hline Did not complete high school & 6.9 & 22.4 & 224.6 & 15.5 & $<0.001$ & 17.7 & 19.6 & 10.7 & 1.9 & 0.449 \\
\hline High school graduate or above & 7.7 & 19.7 & 155.8 & 12.0 & $<0.001$ & 18.4 & 21.7 & 17.9 & 3.3 & 0.308 \\
\hline \multicolumn{11}{|l|}{ Monthly household income (US\$) } \\
\hline Less than 1,500 & 4.2 & 25.7 & 511.9 & 21.5 & $<0.001$ & 15.8 & 17.0 & 7.6 & 1.2 & 0.841 \\
\hline $1,500-3,000$ & 8.5 & 19.2 & 125.9 & 10.7 & $<0.001$ & 17.1 & 18.9 & 10.5 & 1.8 & 0.516 \\
\hline 3,000 or more & 7.5 & 21.8 & 190.7 & 14.3 & $<0.001$ & 22.9 & 26.0 & 13.5 & 3.1 & 0.521 \\
\hline \multicolumn{11}{|l|}{ Self-reported health status } \\
\hline Fair/poor & 5.1 & 13.1 & 156.9 & 8.0 & 0.0184 & 17.1 & 17.9 & 4.7 & 0.8 & 0.987 \\
\hline Good & 6.0 & 21.5 & 258.3 & 15.5 & $<0.001$ & 18.2 & 24.4 & 34.1 & 6.2 & 0.104 \\
\hline Excellent/very good & 8.5 & 23.0 & 170.6 & 14.5 & $<0.001$ & 18.1 & 19.1 & 5.5 & 1.0 & 0.719 \\
\hline \multicolumn{11}{|l|}{ Smoking status } \\
\hline Current smoker & 6.6 & 20.7 & 213.6 & 14.1 & $<0.001$ & 15.2 & 19.3 & 27.0 & 4.1 & 0.346 \\
\hline Former smoker & 6.7 & 22.1 & 229.9 & 15.4 & $<0.001$ & 22.8 & 19.3 & -15.4 & -3.5 & 0.575 \\
\hline Never smoked & 7.5 & 21.3 & 184.0 & 13.8 & $<0.001$ & 17.9 & 21.1 & 17.9 & 3.2 & 0.183 \\
\hline
\end{tabular}

a Flexible sigmoidoscopy or colonoscopy.

$\mathrm{b}$ The percentage changes ([relative risk - 1] × 100) in the rates between 2005 and 2008.

c All $P$ values are two-sided and were calculated for exact comparisons of the rates between 2005 and 2008 . 
Table 4: Full Regression Models for Receipt of FOBT, Endoscopy, and Any test

\begin{tabular}{|c|c|c|c|c|c|c|c|c|c|}
\hline & \multicolumn{3}{|c|}{ Model 1: FOBT } & \multicolumn{3}{|c|}{ Model 2: Endsoscopya } & \multicolumn{3}{|c|}{ Model 3: Any testb } \\
\hline & aOR & $95 \% \mathrm{Cl}$ & $P$ & aOR & $95 \% \mathrm{Cl}$ & $P$ & aOR & $95 \% \mathrm{Cl}$ & $P$ \\
\hline \multicolumn{10}{|l|}{ Gender } \\
\hline Male & 1.00 & Referent & & 1.00 & Referent & & 1.00 & Referent & \\
\hline Female & 0.84 & $0.64-1.11$ & 0.212 & 0.73 & $0.57-0.93$ & 0.011 & 0.72 & $0.58-0.90$ & 0.003 \\
\hline \multicolumn{10}{|l|}{ Age, $y$} \\
\hline $50-59$ & 1.00 & Referent & & 1.00 & Referent & & 1.00 & Referent & \\
\hline $60-69$ & 1.38 & $1.12-1.70$ & 0.003 & 1.45 & $1.20-1.76$ & 0.001 & 1.49 & $1.26-1.75$ & $<0.001$ \\
\hline $70-79$ & 0.94 & $0.67-1.34$ & 0.787 & 0.91 & $0.65-1.27$ & 0.591 & 0.90 & $0.69-1.22$ & 0.471 \\
\hline \multicolumn{10}{|l|}{ Education (years) } \\
\hline $\begin{array}{l}\text { Did not complete } \\
\text { high school }\end{array}$ & 1.00 & Referent & & 1.00 & Referent & & 1.00 & Referent & \\
\hline $\begin{array}{l}\text { High school } \\
\text { graduate or above }\end{array}$ & 1.00 & $0.80-1.24$ & 0.984 & 1.09 & $0.90-1.33$ & 0.390 & 1.03 & $0.87-1.22$ & 0.727 \\
\hline \multicolumn{10}{|l|}{$\begin{array}{l}\text { Monthly household } \\
\text { income (US\$) }\end{array}$} \\
\hline Less than 1,500 & 1.00 & Referent & & 1.00 & Referent & & 1.00 & Referent & \\
\hline $1,500-3,000$ & 0.97 & $0.75-1.24$ & 0.797 & 1.27 & $1.00-1.61$ & 0.053 & 1.13 & $0.92-1.37$ & 0.241 \\
\hline 3,000 or more & 1.11 & $0.83-1.49$ & 0.489 & 1.81 & $1.37-2.38$ & $<0.001$ & 1.51 & $1.19-1.91$ & 0.001 \\
\hline \multicolumn{10}{|l|}{$\begin{array}{l}\text { Self-reported health } \\
\text { status }\end{array}$} \\
\hline Fair/poor & 1.00 & Referent & & 1.00 & Referent & & 1.00 & Referent & \\
\hline Good & 1.41 & $1.01-1.96$ & 0.044 & 0.87 & $0.67-1.14$ & 0.319 & 1.05 & $0.82-1.33$ & 0.702 \\
\hline $\begin{array}{l}\text { Excellent/very } \\
\text { good }\end{array}$ & 1.53 & $1.12-2.08$ & 0.007 & 0.79 & $0.61-1.01$ & 0.064 & 1.02 & $0.82-1.27$ & 0.859 \\
\hline \multicolumn{10}{|l|}{ Smoking status } \\
\hline Current smoker & 1.00 & Referent & & 1.00 & Referent & & 1.00 & Referent & \\
\hline Former smoker & 1.25 & $0.92-1.69$ & 0.153 & 1.06 & $0.79-1.42$ & 0.698 & 1.23 & $0.96-1.57$ & 0.096 \\
\hline Never smoked & 1.21 & $0.89-1.64$ & 0.225 & 1.56 & $1.19-2.06$ & 0.002 & 1.54 & $1.21-1.95$ & 0.001 \\
\hline \multicolumn{10}{|l|}{ Time } \\
\hline 2005 & 1.00 & Referent & & 1.00 & Referent & & 1.00 & Referent & \\
\hline 2006 & 2.13 & $1.55-2.93$ & $<0.001$ & 0.92 & $0.72-1.17$ & 0.508 & 1.31 & $1.06-1.62$ & 0.014 \\
\hline 2007 & 2.98 & $2.19-4.06$ & $<0.001$ & 1.02 & $0.80-1.29$ & 0.900 & 1.42 & $1.15-1.75$ & 0.001 \\
\hline 2008 & 3.57 & $2.64-4.83$ & $<0.001$ & 1.16 & $0.91-1.47$ & 0.204 & 1.94 & $1.58-2.40$ & $<0.001$ \\
\hline-2 log likelihood & \multicolumn{3}{|c|}{3005.931} & \multicolumn{3}{|c|}{3502.828} & \multicolumn{3}{|c|}{4375.334} \\
\hline
\end{tabular}

a Flexible sigmoidoscopy and colonscopy.

b Includes FOBT and/or endoscopy. The number screened does not equal the sum of participants (i.e., people may have had > 1 test).

insurance system, an endoscopy test costs almost 10 times as much as an FOBT test. In addition, the NSCP ensures free-of-charge FOBT testing for all individuals, whereas endoscopy testing is only provided free of charge for those whose FOBT results are positive. Furthermore, the NHI only reimburses colonoscopy and sigmoidscopy testing for those with symptoms or colorectal problems. Therefore, endoscopy use varied with household income, possibly suggesting that the cost of endoscopy is a barrier to CRC screening.

We examined trends in screening for CRC by screening modality and explored the factors associated with uptake 
of CRC screening in a population sample. However, the study's cross-sectional design and reliance on selfreported screening limit the KNCSS. Previous studies have indicated that self-reported FOBT screening data might result in overestimates of the proportion screened $[26,27]$, and recent research has suggested that overreporting may be greater for FOBT than for endoscopy [28]. Therefore, the proportion of subjects who were actually up-to-date for CRC testing may be lower than that indicated by the current analysis. Further, the crosssectional design of the study precludes conclusions about whether any observed associations were causal. Finally, our study sample may not be representative because of low response rate. However, the KNCSS respondents had health characteristics and behaviors that were very similar to those found in other extensively used surveys, such as the Korea National Health and Nutrition Survey.

\section{Conclusion}

Our results demonstrate that CRC screening increased after the introduction of the NCSP, according to a population-based survey. Increasing recognition of the efficacy and importance of CRC screening might have influenced CRC screening rates. However, overall screening rates increased less than did FOBT screening rates. The data indicate increases in both FOBT and endoscopy testing between 2005 and 2008, combined with a shift toward greater use of FOBT compared with endoscopy. This shift might be associated with national CRC screening policies. The introduction of free CRC screening appears to have been effective in increasing CRC screening rates among low-income groups in Korea. However, the increases in FOBT test use have implications for public health practice. Although FOBT is simple, safe, most inexpensive, and its routine use was shown to reduce CRC mortality, it is limited by poorer sensitivity, mainly for premalignant lesions. Colonoscopy, on the other hand, is a more accurate technique, yet invasive, carries a risk of bleeding and perforation, requires preparation and premedication, and involves much higher costs. The options for CRC screening tests allow for flexibility but can also render decisions about recommending or choosing a particular test difficult. Each test has its tradeoffs in terms of efficacy, complications, discomfort, time, and cost [20]. More than half of adults in Korea are still not up-to-date with their CRC tests. It will be important to continue to monitor trends in screening, as well as to investigate factors associated with up-to-date CRC screening. More research will also be required to increase CRC screening rates, particularly among those who had not have CRC screening under NCSP.

\section{Abbreviations}

(CRC): Colorectal Cancer; (NCSP): National Cancer Screening Programme (FOBT): Fecal occult blood test; (FSIG): Flexible sigmoidoscopy; (DCBE): Doublecontrast barium enema; (KNCSS): Korean National Cancer Screening Survey.

\section{Competing interests}

The authors declare that they have no competing interests.

\section{Authors' contributions}

KSC contributed to the conception of study and interpretation, and writing the manuscript. JKJ and HYL participated in the conception of the study and performed the statistical analysis. MIH participated in the design and data collection. SL contributed to the drafting of the manuscript. $\mathrm{HO}$ and ECP participated in the design and coordination of the study. All authors read and approved the final manuscript.

\section{Acknowledgements}

This study was supported by a Grant-in-Aid for Cancer Research and Control from the National Cancer Center, Korea (Grant number: 0710131).

\section{Author Details}

1National Cancer Control Institute, National Cancer Center, 111, Jungbalsan-ro, Ilsandong-gu, Goyang-si, Gyeonggi-do, Korea, 2Department of U-Healthcare Management, College of Medical Science, Soonchunhyang University, Chungnam, Korea and ${ }^{3}$ Research Institute and Hospital, National Cancer Center, 111, Jungbalsan-ro, Ilsandong-gu, Goyang-si, Gyeonggi-do, Korea

Received: 6 January 2010 Accepted: 21 May 2010

Published: 21 May 2010

\section{References}

1. Parkin DM, Bray F, Ferlay T, Pisani P: Global cancer statistics, 2002. CA Cancer J Clin 2005, 55:74-108.

2. Stewart BW, Kleihues P: World Cancer Report Lyon, France: International Agency for Research on Cancer; 2003.

3. Parkin DM, Bray F, Devesa S: Cancer burden in the year 2000: the global picture. Eur J Cancer 2001, 37:S4-66.

4. Shin HR, Won YJ, Jung KW, Kong HJ, Yim SH, Lee JK, Noh HI, Lee JK, Pisani P. Park JG: Members of the Regional Cancer Registries. Nationwide cancer incidence in Korea, 1999-2001: first result using the national cancer incidence database. Cancer Res Treat 2005, 37:325-331.

5. National Cancer Information Center. Cancer incidence 2003-2005 [http://www.cancer.go.kr/cms/data/edudata/1217651 1619.html]

6. Mandel JS, Church TR, Bond JH, Ederer F, Geisser MS, Mongin SJ, Snover DC, Schuman LM: The effect of fecal occult-blood screening on the incidence of colorectal cancer. N Engl J Med 2000, 343:1603-1607.

7. Mandel JS, Bond JH, Church TR, Snover DC, Bradley GM, Schuman LM, Fderer F: Reducing mortality from colorectal cancer by screening for fecal occult blood. Minnesota Colon Cancer Control Study. NEngl J Med 1993, 328:1365-1371.

8. Selby JV, Friedman GD, Quesenberry CP, Weiss NS: A case-control study of screening sigmoidoscopy and mortality from colorectal cancer. $N$ Engl J Med 1992, 326:653-657

9. Newcomb PA, Norfleet RG, Storer BE, Surawicz TS, Marcus PM: Screening sigmoidoscopy and colorectal cancer mortality. J Nat/ Cancer Inst 1992, 84:1572-1575

10. Smith RA, Cokkinides V, Brawley OW: Cancer screening in the United States, 2008: a review of current American Cancer Society guidelines and cancer screening issues. CA Cancer J Clin 2008, 58:161-79.

11. Screening for Colorectal Cancer, Topic Page 2008 [http:// www.ahrq.gov/clinic/uspstf/uspscolo.htm]. U.S. Preventive Services Task Force. Agency for Healthcare Research and Quality, Rockville, MD

12. Tsoi KK, NG SS, Leung MC, Sung JJ: Cost-effectiveness analysis on screening for colorectal neoplasm and management of colorectal cancer in Asia. Aliment Pharmacol Ther 2008, 28:353-363.

13. Sung JJ, Lau JY, Young GP, Sano Y, Chiu HM, Byeon JS, Yeoh KG, Goh KL, Sollano J, Rerknimitr R, Matsuda T, Wu KC, Ng S, Leung SY, Makharia G, Chong VH, Ho KY, Brooks D, Lieberman DA, Chan FK: Asia Pacific Working Group on Colorectal Cancer. Asia-Pacific consensus recommendations for colorectal cancer screening. Gut 2008, 57:1166-1176. 
14. Lee BW, Jeong SY: Korean national recommendation guidelines on screening and surveillance for early detection of colorectal cancer. J Korean Med Assoc 2002, 45:981-991.

15. Yoo KY: Cancer control activities in the republic of Korea. Jpn J Clin Oncol 2008, 38:327-333.

16. Vernon SW: Participation in colorectal cancer screening: a review. J Nat/ Cancer Inst 1997, 89:1406-1422.

17. Lemon S, Zapka J, Puleo E, Luckmann R, Chasan-Taber L: Colorectal cancer screening participation: comparisons with mammography and prostate-specific antigen screening. Am J Public Health 2001, 91:1264-1272.

18. Seeff LC, Nadel MR, Klabunde CN, Thompson T, Shapiro JA, Vernon SW, Coates RJ: Patterns and predictors of colorectal cancer test use in the adult U.S. population. Cancer 2004, 100:2093-2103.

19. Lafata JE, Williams LK, Ben-Menachem T, Moon C, Divine G: Colorectal carcinoma screening procedure use among primary care patients. Cancer 2005, 104:1356-1361.

20. Meissner HI, Breen N, Klaunde CN, Vernon SW: Patterns of colorectal cancer screening uptake among men and women in the United States. Cancer Epidemiol Biomarkers Prev 2006, 15:389-394.

21. Jerant AF, Fenton JJ, Franks P: Determinants of racial/ethnic colorectal cancer screening disparities. Arch Intern Med 2008, 168:1317-1324.

22. Ioannou GN, Chapko MK, Dominitz JA: Predictors of colorectal cancer screening participation in the United States. Am J Gastroenterol 2003, 98:2082-2091.

23. Hahm MI, Choi KS, Park EC, Kwak MS, Lee HY, Hwang SS: Personal background and cognitive factors as predictors of the intention to be screened for stomach cancer. Cancer Epidemiol Biomarkers Prev 2008 17:2473-2479.

24. 2005 Resident registration population: Korea National Statistical Office. Seoul; 2005

25. Smith RA, Cokkinides V, Brawley OW: Cancer screening in the United States, 2009: a review of current American Cancer Society guidelines and issues in cancer screening. CA Cancer J Clin 2009, 59:27-41.

26. Mandelson MT, LaCroix AZ, Anderson LA, Nadel MR, Lee NC: Comparison of self-reported fecal occult blood testing with automated laboratory records among older women in a health maintenance organization. Am J Epidemiol 1999, 150:617-621.

27. Montano DE, Phillips WR: Cancer screening by primary care physicians: A comparison of rates obtained from physician self-report, patient survey, and chart audit. Am J Public Health 1995, 85:795-800.

28. Vernon SW, Tiro JA, Vojvodic RW, Coan S, Diamond PM, Greisinger A, Fernandez ME: Reliability and validity of a questionnaire to measure colorectal cancer screening behaviors: Does mode of survey administration matter? Cancer Epidemiol Biomarkers Prev 2008, 17:758-767.

Pre-publication history

The pre-publication history for this paper can be accessed here: http://www.biomedcentral.com/1471-2458/10/265/prepub

doi: $10.1186 / 1471-2458-10-265$

Cite this article as: Choi et al., Increasing uptake of colorectal cancer screening in Korea: a population-based study BMC Public Health 2010, 10:265

\section{Submit your next manuscript to BioMed Centra} and take full advantage of:

- Convenient online submission

- Thorough peer review

- No space constraints or color figure charges

- Immediate publication on acceptance

- Inclusion in PubMed, CAS, Scopus and Google Scholar

- Research which is freely available for redistribution

Submit your manuscript at www.biomedcentral.com/submit
C) Biomed Central 